\title{
Asynapsis in Normal and Irradiated Luzula nivea
}

\author{
F. S. Bokhari $i^{1}$ and S. Ahmad \\ School of Biological Sciences, Queen Mary College, University of London, \\ Mile End Road, London, E1 4NS, U.K.
}

Accepted March 9, 1990

Asynapsis and desynapsis have been reported in many higher plants having localised centromeres. In normal plants such as in maize Beadle 1932 and in rye Prakken 1943 while radiation-induced mutations were found in wheat Martini and Bozzini 1966, in pepper Morgan 1963, in barley Swietlinska and Evans 1970, Srivastava 1974, in cieer Ahmad 1979, in peppers Kumar and Rao 1985 and few other to qoute.

In family Juncaceae no such previous work has been published; some cytological work has been published previously for Juncaceae by Bokhari 1979, Bokhari and Godward 1980, Castro et al. 1948, Nordenskiöld 1951, 1964, Montezuma de Carvalho 1961, Lambert 1971, Braselton 1971 and many others.

In Luzula nivea as in all other species of Juncaceae, the tetrads of the pollen mother cells are enclosed by an exine to form a single pollen grain, which is at first 4 -nucleate and afterwards 8-nucleate.

According to some authors (Malheiros and Castro 1947), the four central nuclei degenerate leaving an immature pollen grain containing four nuclei, and after this the intine differentiates each pollen grain.

The chromosome number of Luzula nivea was already known (Nordenskiold 1949, Wagner 1949, Bokhari 1979). This paper deals with cytological studies in asynaptic normal and irradiated Luzula nivea.

\section{Materials and methods}

Mature air-dried seeds of Luzula nivea $(2 n=12)$ were kept in dessicator until seed weights were constant. These seeds were then given to $\gamma$-irradiation for ${ }^{80} \mathrm{Co}$ source of Queen Mary College, London, doses ranging from 30 to $120 \mathrm{kR}$. Seeds were then sown in a closed greenhouses at $20^{\circ} \mathrm{C} \pm 5^{\circ} \mathrm{C}$. For the meiotic studies, inflorescences were fixed in acetic alcohol $(1: 3)$ plus a few drops of aqueous ferric chloride for 24 hours. The anthers were stained in acetocarmine. All the photographs were taken under standard magnification $(\times 3000)$.

\section{Results}

Meiosis and pollen grain development in Luzula nivea was studied in the control, and following $30 \mathrm{kR}$ in the $\mathrm{M}_{1}$ generation. Because of the length of time taken before flowering and the low percentage of flowering plants, few buds were fixed for cytological investigation.

In the control, from the four plants that flowered out of twenty-six, two were used for meiotic fixation, while at $30 \mathrm{kR}$ only two plants produced flowers. After fixing for meiosis the rest of the flower buds were kept for seeds for the $M_{2}$ generation.

In the synaptic material, six bivalents were highly contracted, short and rounded. Buds from one of the inflorescence branches of the control and the $M_{1}$ following $30 \mathrm{kR}$ were asy-

${ }^{1}$ Present address: Institute of Pure and Applied Biology, Bahauddin Zakariya University, Multan, Pakistan. 
naptic. In the control, all 12 univalents were seen at diakinesis (Fig. 1) they are long and fairly thick.

In the asynaptic material at $30 \mathrm{kR}$ sometimes 12 univalents were present (Fig. 2). Not even one chiasma could be clearly observed; the occurrence could not be excluded.

At $30 \mathrm{kR}$, some of the buds showed remarkable features at diakinesis or metaphase I. In Fig. 3 the relatively thick well-defined "chromosomes" are grouped. There is in this photograph the possibility that six such groupings are present; 4 are clearly visible and the other two could be those overlapping the nucleous. Normally, there would be six bivalents, so that here if each of the "chromosomes" is regarded as a chromatid, each bivalent is indeed represented by four chromatids. In Fig. 4 there is diakinesis with diplochromosomes. In Fig. 5, about thirty six chromatids can be counted; these are in pairs more or less in six groups. Sometimes although less well separated, the number and arrangment of chromatids is similar.

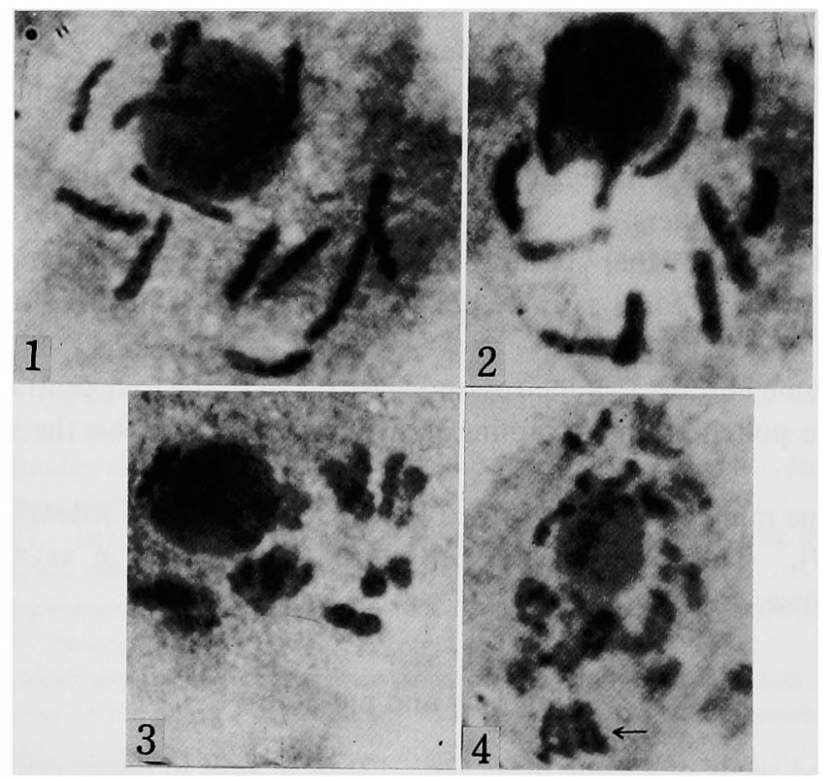

Figs. 1-4. 1, Luzula nivea. Control showing 12 univalents at diakinesis. 2. L, nivea, $30 \mathrm{kR}$, showing 12 univalents at diakinesis. 3, $30 \mathrm{kR}$, diakinesis? diplochromosomes. 4, $30 \mathrm{kR}$, diakinesis with? diplochromosomes, showing (arrow) four chromatids lying parallel to each other. $\times 3000$.

Judging by the appearance of the nucleolus the stage is diakinesis. In the normal control material, the six bivalents at this stage are all highly contracted and small in size; neither chromatids nor indeed chromosomes can be distinguished in them. In Fig. 4 there is diakinesis with diplochromosomes (arrow); all four "chromatids" are seen clearly lying parallel. They are so thick that proliferation of strands within them seems likely. No chiasmata can be observed, raising the possibillity of de-synapsis following pairing, although it is possible that this material was asynaptic.

About thirty six chromatids can be counted (Fig. 5); these are in pairs more or less in six groups. Sometimes although less well separated, the number and arrangment of chromatids is similar. Judging by the appearance of the nucleolus the stage is diakinesis. These diplobivalents of irradiated Luzula are somewhat contracted, much nearer in dimensions to the bivalents of the normal synaptic $L$. nivea, than the long univalents of the asynaptic material (Fig. 1 and 2) at the same stage, and neither chromatids nor indeed chromosomes can be dis 
tinguished in them.

In a few PMC's heteropyknotic degeneration of the chromosomes into contracted masses perhaps following anaphase II was observed (Fig. 6).

In Juncaceae as a rule all the tetrad nuclei formed in the pollen mother cells are included in the pollen grains.

In L. nivea, in both control and irradiated material, each of the tetrad nuclei underwent a further division as normally happens and eight nuclei were formed (Fig. 7).

Generally the attitude of the spindles of these divisions shows that, when the division is completed, four nuclei lie in the central position and four at the periphery.

In the material with "diplobivalents", more than eight nuclei (upto 10 or 12) are found at this stage. They are of different sizes suggesting an irregularity of segregation rather than additional mitosis.

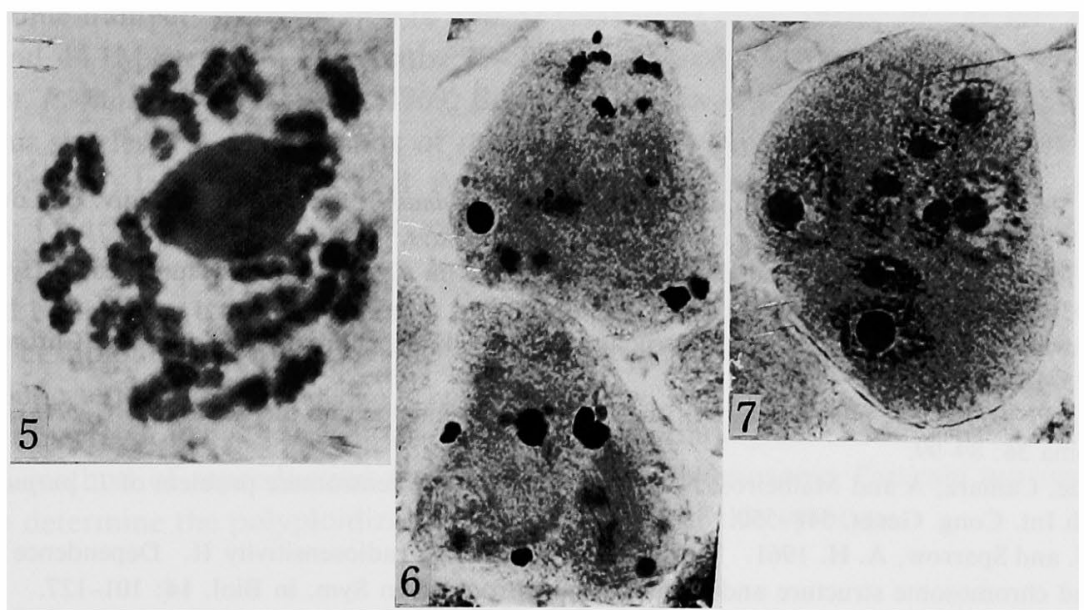

Figs. 5-7. 5, L. nivea, $30 \mathrm{kR}$, diakinesis? diplochromosomes, 36 chromatids can be counted. 6 , L. nivea, $30 \mathrm{kR}, \mathrm{PMC}$ in tetrad stage showing heteropyknotic degeneration. 7, L. nivea, $30 \mathrm{kR}$, development of pollen grain in diplobivalent material. $\times 3000$.

\section{Discussion}

Irradiation caused breakage and the number of chromosomes increased in the plants with diffuse centromere by the addition of mitotically viable fragments but this structural change simply could not give sterility in the material with diffuse centromere (Nordenskiöld 1957 and 1964).

No published work on asynapsis in diffuse centromere is found, while number of work has been done on asynaptic material having localised centromere.

The extreme sensitivity of $L$. nivea in the present study could be partly due to unstable asynapsis found in the control material which can be responsible for its low germination percentage (Bokhari 1979); same results are also found in the control material of Capsicum frutescens (Kumar and Rao 1985) where the plants were weak in texture and were showing slow growth.

The association of 4 large chromosomal structures observed here (Fig. 5), recalls the "diplochromosomes" of Barber 1940. These were produced in Fritillaria plants, following 2 days of treatment at $30^{\circ} \mathrm{C}$, beginning at pachytene and continued to tetrad formation. It resulted in diplobivalents, in which such chromosome was represented by four chromatids. In present study of $L$. nivea it was the seed not the growing plants, supporting the suggestion 
that genetic change was responsible for the chromatid prolifiration at meiosis; this gene mutation has also been confirmed in Capsicum frutescens Kumar and Rao 1985.

The environmental factor also has some effect on desynapsis in Pearl Millet (Vishnuvardhan and Lakshmi 1987).

\section{Summary}

The whole position in $L$. nivea can be summed up as follows. In the control material, parts of the otherwise normal inflorescence contained asynaptic pollen mother cells; the implication being that the asynapsis was due to a mutant gene, present in a sector of the inflorescence. In the irradiated material, in the $M_{1}$ generation, in accordance with expectation that the plants will be chimaeras, buds are found on the same plant which may be normal, or asynaptic, or produce diplobivalents, or in which the daughter nuclei degenerate following meiosis.

\section{References}

Ahmad, S. 1979. Radiation studies in cultivars of Cicerariethinum. Ph. D. Thesis, Univ. of London. Beadle, G. W. 1932. A gene for sticky chromosomes in Zea mays. Z. Indukt. Abst.

Bokhari, F. S. 1979. Karyotype and dose tolerance studies in Cyperaceae and Juncaceae. Cytologia 44: 103-109.

- and Godward, M. B. E. 1980. The ultrastructure of diffuse kinetochore in Luzula nivea. Chromosoma 79: $125-136$.

Braselton, J. P. 1971. The ultrastructure of the non-localised kinetochore of Luzula and Cyperus. Chromosoma 36: $89-99$.

Castro D. de, Camara, A and Malheiros, N. 1948. X-rays in the centromere problem of L. purpurea. Proc. 8 th Int. Cong. Genet. 548-550.

Evans, H. J. and Sparrow, A. H. 1961. Nuclear factors affecting radiosensitivity II. Dependence on nuclear and chromosome structure and organisation. Brookhaven Sym. in Biol. 14: 101-127.

Kumar, O. A. and Rao, K. G. R., 1985. Desynapsis in Capsicum frutescense. Cytologia 50: 69-73.

Lambert, A. M. 1971. Contribution à l'é etude du centromère diffuse ches les Luzules: Observations sur Luzula albida. C. R. Acad. Sci. (Paris) Ser. D. 272: 403-406.

Malheiros, N, and Castro D. de. 1947. Chromosome number and behaviour in Luzula purpurea Link. Nature 160: 156 .

Martini, G. and Bozzini, A. 1966. Radiation induced asynaptic mutant in Durum Wheat (Triticum durum). Chromosoma 20: 251-266.

Montezuma de Carvlho 1961. X-rays induced breakage in chromosomes with diffuse centromeres. Effect of ionizing radiation of seeds. Proc. Sym. Karlsruhe 1960, IAEA. Vienna 271-277.

Morgan, D. T. Jr. 1963. Asynapsis in pepper flowering X-irradiation of the pollen. Cytologia 28 : $102-107$.

Nordenskiöld, H. 1949. The somatic chromsomes of some Luzula sp. Bot. Not. 81-92.

- 1951. Cytotaxononicals in genus Luzula I. Somatic chromosome and chromosome number. Hereditas 37: 325-355.

- 1957. Changes in somatic chromosome patterns in root tips of X-ray treated Luzula. Ann. Roy. Agric. Coll. Sweeden 22: 273-289.

- 1964. The effect of X-irradiation on diploid and polyploid Luzula. Hereditas 49:33-47.

Prakken, R. 1943. Studies of asynapsis in rye. Hereditas 29: 475-495.

Srivastava, H. M. 1974. Radiation induced mutants in barley. Cytologia 39:63-68.

Swietlinska, Z. and Evans, H. J. 1970. Induction of chromosomes aberrations by X-rays and chemical mutagens in a desynaptic mutant in wild-type barley. Mut. Res. 10: 185-196.

Vishnuvardhan, Z. and Lakshmi, N. 1987. Environmental influence on a desynaptic double trisomic Pearl Millet. Cytologia 52: 571-575.

Wagner, M. 1949. Subsidio para estudo ciotogico de género Luzula. D. C. 1. Genetica Iberica 1: 59-67. 